\title{
Practical Research on Blended Learning Based on WeChat Public Platform
}

\author{
Liangtao Yang \\ Engineering \& Training Center \\ Shanghai Polytechnic University \\ Shanghai, China \\ E-mail: ltyang@sspu.edu.cn
}

\begin{abstract}
With the development of the "Internet + education", mobile learning with its unique way is leading a huge change in digital learning. Social software, such as smart phones and tablet computers, has gradually affected all aspects of people's lives and studies, especially the emergence of WeChat public platform, which provides a new direction for the reform of higher education. This paper fully excavate the educational function of WeChat public platform, and based on mobile learning theory, connectivism learning, build "before class, in class, after class" blended learning model. Taking "computer application foundation" course as an example, this paper proves that blended learning based on WeChat public platform can stimulate students' learning initiative and the enthusiasm, effectively promote students' learning.
\end{abstract}

Keywords-WeChat public platform; blended learning; mobile learning

\section{INTRODUCTION}

With the continuous development of Internet communication technology and intelligent terminal, the influence of time and space limitation is becoming smaller. The interactions between people become more and more simple, the way of getting information have taken place great changes. Experts and scholars begin to attach importance to the combination of new media and traditional teaching, it also provides a new the opportunity for the development of higher education informatization. In the traditional teaching, teachers and students extracurricular interactive less, self-learning ability of students is poor, China has invested a lot of manpower and resources to research and develop the blended learning, but the final learning effect is not obvious. Under this background, this paper fully excavate the educational function of WeChat public platform, and based on mobile learning theory, connectivism learning, build "before class, in class, after class" blended learning model. Taking "computer application foundation" course as an example, this paper carries out practical research to stimulate students' learning initiative and enthusiasm, improve the students' participation and expand the depth and breadth of learning [1].

\section{WECHAT PUBLIC PLATFORM AND BLENDED LEARNING}

\section{A. WeChat Public Platform}

WeChat is instant messaging service software which is launched by Tencent Inc in early 2011 . The software can send fast voice text messages, video, pictures and text by smart phones. WeChat is a product with the development of mobile internet, is a way of life, and is also a new way of communication [2]. With the arrival of the micro era, WeChat will bring high efficiency of information transmission and diversification. At the same time, WeChat has also helped to change our communication way.

WeChat public platform integrates social, friends and group management into one, and has become one of the most important platforms of information dissemination in mobile Internet era. It successful put people, equipment, life, industry, education, society and the interconnection of all things together.

\section{B. Blended Learning}

The development of blended learning model has a certain degree of history, and its application in the field of education is drawn from enterprise training. At that time, pure traditional training methods could not meet the benefits of enterprises, and the training results and economic benefits of simple "ELearning" were deeply thought by managers of foreign enterprises. Considering the economic benefits of enterprises, the combination of traditional training and network teaching can improve the economic efficiency of enterprises, so the "blended learning" is put forward".

The definition of the blended learning is: Blended learning focuses on optimizing achievement of learning objectives by app lying the "right" learning technologies to match the "right" personal learning style to transfer the "right" skills to the "right" person at the "right" time. Based on the research results of blended learning both at home and abroad, we can summarize some understanding of blended learning: [3]

The blended learning of online and offline: online learning refers primarily to web-based instruction, and offline learning refers to classroom instruction. The traditional offline teaching and online teaching are organically combined to improve the learning efficiency.

The mixture of teaching media: the development of technology enriches the teaching media of blended learning. In accordance with the time and space structure and the level of interaction, the teaching media can be divided into synchronous and asynchronous teaching media, including traditional classroom, video, virtual reality, multimedia classroom and Internet video conferencing system. 
The mixture of learning environment: in the traditional teaching environment, especially in the classroom teaching environment, teachers and students can complete face-to-face interaction, make up for the network teaching virtualization, interaction defects.

\section{Blended Learning Based on WeChat Public Platform}

WeChat has become an indispensable tool for communication and information acquisition among college students. WeChat public platform has the characteristics of convenient operation, efficient interpersonal communication, rich content push and accurate message push. The application of WeChat public platform in higher education has expanded the social interaction space between teachers and students, and provided mobile learning support [4]. The platform provides mass information function, various automatic response settings, user management and material management functions, and provides statistical analysis functions such as user analysis, graphic analysis, information analysis and interface analysis.

With the rapid development of computer technology and the gradual maturity of Internet technology, more and more people are aware of the importance of blended learning. Based on the widely used mobile communication technology of WeChat public platform, this paper proposes a blended learning model supported by WeChat public platform. This learning model is blended with mobile learning, flip learning and classroom learning. It combines the 3 aspects of "before class, in class and after class", and gives full play to the teacher's leading, monitoring and inspiring role. At the same time, the learning model mobilizes the enthusiasm and initiative of students to achieve the optimization of the teaching process and teaching effect.

\section{THE DESIGN OF LEARNING MODEL}

\section{A. The Basic Theory}

The first is mobile learning. Mobile learning is a new form of learning which uses wireless mobile communication network technology and wireless mobile communication equipment to obtain educational information, educational resources and educational services. Contemporary college students, called the original people generally in mobile Internet era, have high information literacy, use the network frequently, are highly dependent on the network by means of network; the mobile Internet has become an indispensable group of college students learning, life and entertainment [5]. With its unique and innovative way, mobile learning is leading the great change of digital learning. Researchers should actively explore the corresponding learning mode from the perspective of teaching.

The second is connectionism. Under the environment of Internet + education, teaching and learning are facing new challenges in the information environment. Connectionism describes that learning should be connected to the Internet in the Internet age, the learning should be a teaching \& learning interaction, a specialized communication node or source of information about the network formation process, be also a process of exploring knowledge and knowledge acquisition and management of constant and continuous [6]. Today, the mobile Internet based on smart phones is no longer a technical tool for contemporary college students, but more a lifestyle based on modern information and communication technology. In the mobile learning environment, the polymorphism of the students' learning mode has become the new normal, and the corresponding learning model should also be changed accordingly.

\section{B. The Design of Learning Process}

Mobile learning theory and connectionism theory provides a theoretical basis for the "blended learning in "Internet + education" environment, and as the connection platform, WeChat public platform provides a practical foundation for blended learning. In this study, a hybrid learning model based on WeChat public platform is constructed, which is shown in Figure 1, in combination with the diversity of students' mobile learning methods and the mixing of teachers' teaching methods.

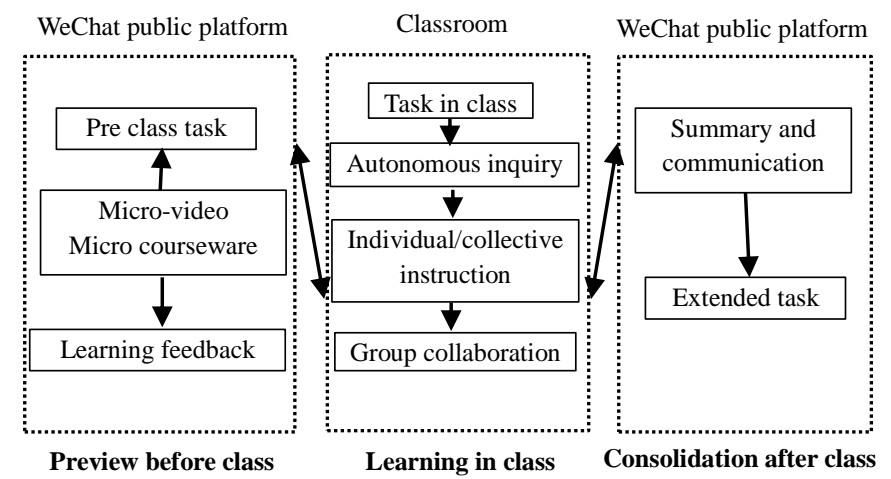

Fig. 1 The blended learning model

The blended learning model based on WeChat public platform consists of three parts:

The first is preview before class. Before the class, the teacher uses the WeChat public platform to share the prepared text, voice, video or pictures to the students, and teach students receive, preview and download. Teachers use the WeChat public platform to share the key and difficult points of this lesson to help students focus on the difficult points while previewing. The students in the preview stage, there are some who don't understand problems can be feedback to the teacher by the WeChat platform, students and teachers in the process of communication, can take anonymous communication or real name communication, and anonymous communication can avoid the shy of the students in face-to-face communication. Real name communication can help the teacher guide and answer in a different way. According to the student's preview feedback, the teacher can prepare the class content in time and in full. The teacher will explain some common problems in class, and answer some individual questions and answer them one by one, so as to arouse the enthusiasm of students and improve their learning efficiency.

The second is learning in class. Before presenting the new lesson, the teacher simply tests the students' preview and records them by asking questions. The teacher will explain the new knowledge content according to the traditional mode, and observe the students' response, and finally answer the questions that the students will encounter in the pre class preparation stage and lectures, so as to improve the learning efficiency. This kind of teaching model is more targeted, and it is no longer a 
traditional classroom teacher lectures, students listen to lectures, and become a student oriented, teacher led dual master teaching. In classroom teaching, teachers can take group cooperative learning methods, so that students can discuss problems and make their own summary. In the blended learning based on WeChat public platform, teachers should give students full time and space in class. In class, students' activities are mainly to discuss, display and answer questions with teachers and other students, so as to realize the internalization of knowledge.

The last is consolidation after class. At the end of the traditional classroom teaching, mainly students complete the assignment in the classroom, and teachers do not have much communication. In blended learning based on the WeChat public platform, teachers publish jobs online through the WeChat public platform. When students encounter problems, students can download learning materials or use view issues the function of intelligent automatic reply answer in the WeChat public platform, can also interact with the teacher by WeChat online, timely solve the problems. In the course of communication, students can choose to chat with their teachers or classmates. In the process of self-study, students will feedback the problems encountered in the study to the teachers so that the teachers can adjust the teaching design of the next class in a timely manner.

\section{THE TEACHING CASE}

As a new thing in the field of information technology, WeChat public platform has brought new opportunities for the education. Considered that the "computer application foundation" course have less class, more teaching content, more students and other factors, the author takes the course as a case study of blended learning supported by the WeChat public platform.

\section{A. Preparation before Class}

In our university, "Computer application foundation" is a public computer courses for the students of non-computer majors. The course teaching is mainly based on practical operation, which mainly trains students to apply computer technology to solve practical problems. The course teaching content is very rich, and the student must study word2010, excel2010, powerpoint2010, photoshopcs4 and flashcs4 altogether five commonly used software. However, the "computer application foundation" course as a public course, the teaching arrangements and standards is the weekly class, 3 class hours every time, a total of 32 hours, which means students only once a week after school classroom teaching, teachers and students have also no good interactive platform, and therefore cannot meet students solve the problems timely; at the same time, due to the limited class, the number of teachers' demonstration and guidance is limited, only to guide students to do some basic, imitation project and cannot expand the knowledge point and surface. With the passage of time, students are prone to forgetfulness, and learning is not deep enough, systematic, which led to a significant reduction in learning effectiveness. Considering these problems, with the help of WeChat public platform, before the classroom teaching, teachers release micro video, teaching courseware and related knowledge, in order to ensure the students clear learning tasks, and learn micro courseware and micro teaching video, teachers can also supplement the necessary learning resources. After the completion of micro courseware and micro teaching video learning, students complete small tasks before class. Students will submit their knowledge and questions that are not yet understood to the WeChat public platform in order to interact with teachers and other students.

\section{B. Classroom Learning}

Because students have study and discussed relevant issues, set up the related knowledge with the help of micro courseware released on WeChat public platform, the classroom teaching is still using the traditional multimedia network classroom demonstration. The classroom link focuses on solving the common problems encountered by students, and teachers should set aside enough time for students to practice and complete the operation, while the teacher gives real-time guidance, comments and analysis. Then, the teachers focus on the review of the knowledge points, and targeted to explain the students before class and hands-on practice in the process of feedback difficult problems. Finally, teachers are targeted to supplement the diverse teaching resources to help students further understand and consolidate knowledge. For students who have difficulty learning individually, the teacher gives individualized guidance. From the point of view of the implementation of classroom teaching, students' enthusiasm is high and the classroom atmosphere is lively.

\section{After-class Consolidation}

The end of classroom teaching does not mean the end of communication between teachers and students. After class, the students' learning results can be displayed by various forms in the WeChat public platform, and the teachers will review and comment on the results. After class, the teacher can also collect student feedback problems by using WeChat public platform, completes the class feedback records, and the combination of these problems and the classroom teaching situation of teaching summary. According to the needs of the teaching, the teacher can supplement related curriculum resources to expand the depth and breadth of learning, and constantly improve the curriculum system. Students can use the WeChat public platform to complete the classroom test, and put forward more requests to the teachers. Students can discuss the problems encountered in the process of autonomous learning with teachers and other students, so the blended learning based on WeChat public platform can better meet the needs of students' individualized learning.

\section{CONCLUSION}

Through the exploration and practice of a semester, the study found that the blended learning based on the WeChat public platform has the following advantages: it can improve the students' autonomous learning ability; optimize the learning experience; promote the teaching interaction and form a fusion reality curriculum ecosystem. The arrival of the micro-era promotes the deep integration between modern information technology and higher education, which is not only the development trend for education in future, but also the development direction of teaching reform. Popularity and quick communication features of WeChat make blended learning based on WeChat Public Platform more convenient, which greatly accelerates the learning speed, promotes the process of 
teaching reform of higher education, and helps to improve the teaching quality of high education. In this paper, the author conducted a preliminary exploration and practice on application of public platform in the field of higher education, I firmly believe that WeChat Public Platform will have very broad prospects with its increasing maturity in the field of higher education, and all of these implementations rely on bold research and practice for educator.

\section{REFERENCES}

[1] Yuting Liu. Research on the application of WeChat public platform in mobile learning [J], education technology, 2013,(10):91-93.

[2] Yuan Lei, Xiaohui Chen, Yanli Zhang. Research on blended learning based on WeChat[J], China Educational Technology, 2012,(7):65-69.

[3] Peiyao Su. Discussion on blended learning based on MP learning platform[J], Experimental Technology and Management, 2015,(6):177180.

[4] Bai Hao, Jingjing Hao. Research on the application of WeChat public platform in the field of Higher Education [J].The Chinese Journal of ICT in ducation, 2013,(4):78-81.

[5] Fengyan Mao. Research on the Informationization Teaching based on WeChat Public Platform[J].Vocational Technology,2015,(11):62-62.

[6] Meidan Xu, Yichun Zhang, Guoshuai Lan. Towards a Blended Learning Model Based on WeChat Public Platform[J], Distance Education in China,2015,(4):36-42. 